ARCHIVO ESPAÑOL DE ARTE, LXXXIX, 354

ABRIL-JUNIO 2016, pp. 194-201

ISSN: 0004-0428, eISSN: 1988-8511

doi: $10.3989 /$ aearte. 2016.13

\title{
DOS NUEVOS DIBUJOS DEL PINTOR PEDRO RUIZ GONZÁLEZ
}

\author{
Cristina Agüero Carnerero \\ UNED \\ cristina.aguero@geo.uned.es
}

\begin{abstract}
En el presente artículo se atribuyen al pintor Pedro Ruiz González (h.1640-1706), discípulo de Escalante y de Carreño, dos dibujos de la Biblioteca Nacional de España antes considerados obra de Francisco Rizi.

Palabras clave: Pedro Ruiz González; Francisco Rizi; Dibujo; Modelo de presentación; Biblioteca Nacional de España.
\end{abstract}

\section{TWO NEW DRAWINGS BY THE PAINTER PEDRO RUIZ GONZÁLEZ}

The author attributes to the painter Pedro Ruiz González (c.1640-1706), follower of Escalante and Carreño, two drawings previously ascribed to Francisco Rizi in the National Library of Spain.

Key words: Pedro Ruiz González; Francisco Rizi; Drawing; Model; National Library of Spain.

En su Historia del dibujo en España Pérez Sánchez subrayaba lo complicado que resulta individuar la autoría de los numerosos dibujos realizados en Madrid en las últimas décadas del XVII que han llegado hasta nosotros ${ }^{1}$. Como resultado de las dificultades que plantea esta empresa, en ocasiones se han englobado en el corpus gráfico de los principales maestros de la escuela folios de calidad notablemente inferior a los salidos de sus manos. Éste es el caso de dos apuntes pertenecientes a la Biblioteca Nacional de España catalogados por Barcia como obra de Francisco Rizi ${ }^{2}$ y que aquí atribuimos a Pedro Ruiz González, discípulo de Escalante que completó su formación bajo las directrices de Carreño ${ }^{3}$. Palomino fue el primero en poner de manifiesto la fecundidad como dibujante de este artista, alabando también su capacidad inventiva y la erudición de sus composiciones, que se evidencia especialmente en sus estudios preliminares al óleo o "borroncillos", entre los que el tratadista destaca uno "del Pretorio de Pilatos con Cristo Señor nuestro, cuando le iban a poner la Cruz a cuestas" que parangona con la obra de Veronés ${ }^{4}$. La pieza citada por Palomino ha sido identificada

\footnotetext{
${ }^{1}$ Pérez Sánchez, 1986: 258.

2 Barcia, 1906: 97, nº 461 y 463. En el mismo catálogo Barcia recoge tres folios de Ruiz González (p. 99, nº 471473) que considera "malísimos", y de uno de ellos, firmado, dice que es "abominable".

3 Sobre Pedro Ruiz González véase: López Sánchez, 2007. Quesada Varela, 1999: 213-224. Barrio Moya, 1995: 413423. Sullivan/Mallory, 1982: 103-104. Agulló Cobo, 1978: p. 100. Urrea Fernández, 1975: 707-712. Pemán, 1944: 179180. Sánchez Cantón, 1943: 399-403.

${ }^{4}$ Palomino, 1988 ( $1^{\mathrm{a}}$ ed. 1724): 547. Ceán Bermúdez secundó los elogios de su predecesor a los "borroncillos" de Ruiz González, "que parecen de los grandes maestros de la escuela veneciana", y equiparó la habilidad del artista para crear estas piezas con su facilidad para "tocar los dibujos con lápiz y aguada". Ceán, 1800: 284. En diccionario de términos relativos al arte de la pintura que incorpora en su obra, Palomino define "borroncillo o borrón" como "la traza, ó mancha de colorido, donde el pintor hace la invención para algun asunto, que ha de executar en mayor tamaño".
} 


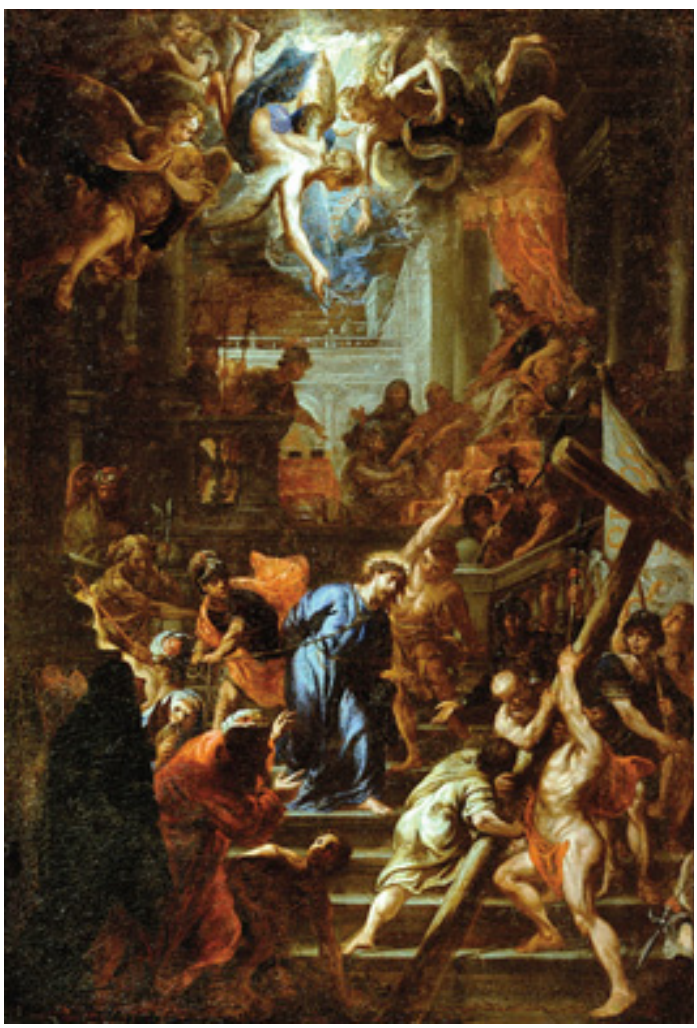

Fig. 1. Pedro Ruiz González, Cristo en el Pretorio. Museo Nacional del Prado, Madrid.

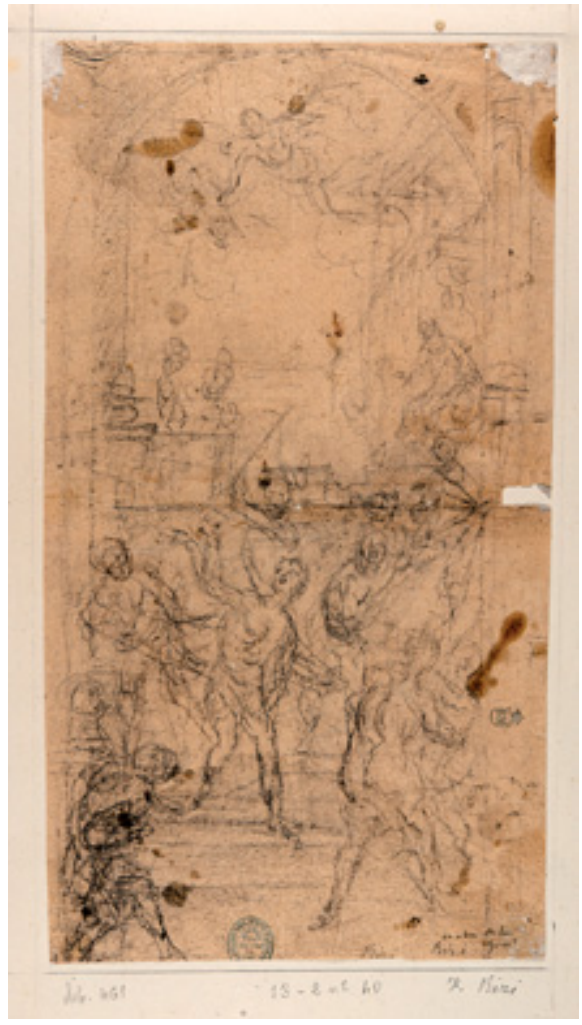

Fig. 2. Aquí atribuido a Pedro Ruiz González, Estudio para martirio de un santo. Biblioteca Nacional de España, Madrid.

con una pintura del Museo Nacional del Prado que efectivamente muestra una notable deuda con la escuela veneciana en la intensidad de las tintas rojas y azules y en el protagonismo concedido a la arquitectura (fig. 1) $)^{5}$, y que por su cuidada factura y detalle en la descripción de la escena, probablemente se trate del modelo de presentación mostrado al comitente para que diera su visto bueno a la composición ideada por el artista antes de la ejecución del cuadro definitivo. Se conocen sobresalientes ejemplos de modelos de presentación correspondientes a artistas que al igual que Ruiz González trabajaron en Madrid en la segunda mitad de la centuria, entre los que se cuentan el pintado por Carreño para La fundación de la Orden Trinitaria de $1666^{6}$, el firmado por Coello en 1668 para

${ }^{5}$ Óleo sobre lienzo, 123 x 83 cm., $n^{\circ}$ inv. P2807. Véase: López Sánchez, 2007: 30-31, 124-126. Pérez Sánchez, 1986b: 339. Sánchez Cantón, 1943: 401-402.

${ }^{6} \mathrm{El}$ boceto se encuentra en la Akademie der bildenden Künste Wien (óleo sobre lienzo, 106 x $86 \mathrm{~cm}$., $\mathrm{n}^{\circ}$ inv. GG511) mientras que el cuadro pintado para el altar de la iglesia de los trinitarios descalzos en Pamplona, firmado y fechado por Carreño, se conserva en el Musée du Louvre (óleo sobre lienzo, 500 x 315 cm., nº inv. R.F. 1964-36). Véase: Baticle, 1964: 140-153; 1965: 15-34. Francisco Rizi participó también en este encargo proporcionando la idea primegenia para la composición, que plasmó en un dibujo perteneciente a la Galleria degli Uffizi (Pluma, aguada y tinta parda, dibujo preliminar y cuadrícula a lápiz, sobre papel verjurado, 440 x $300 \mathrm{~mm}, \mathrm{n}^{\circ}$ inv.10164 S). Sobre este último véase: Pérez Sánchez, 1972: 103-104, nº 116, fig. 87; 1980: 103, nº 227, lám. LXXX.

Arch. esp. arte, LXXXIX, 354, ABRIL-JUNIO 2016, 194-201

ISSN: 0004-0428, eISSN: 1988-8511, doi: 10.3989/aearte.2016.13 
la Encarnación de San Plácido 7 , y el realizado por Rizi en 1671 para el Martirio de San Ginés que ocupa el altar mayor de la iglesia madrileña bajo la advocación de este santo ${ }^{8}$.

Las medidas del modelo de Ruiz González en el Prado son similares a las de los citados ejemplos y al igual que éstos está firmado y fechado (1673), lo que por otra parte no es excepcional en las obras de este artista ${ }^{9}$. Aunque se desconoce la pintura para la que fue realizado, todo apunta a que al igual que los de Carreño, Coello y Rizi, era preparatorio para un cuadro de altar de grandes dimensiones, formato al que se ajustaría bien la compleja composición proyectada por el pintor, que ideó una escena vibrante y llena de movimiento gracias a la sabia disposición de las figuras y hábil modulación de la luz. Se trata sin duda de una invención meditada y prueba de ello es el rasguño conservado en la Biblioteca Nacional que hasta ahora se había considerado preparatorio para el ya mencionado Martirio de San Ginés (fig. 2) ${ }^{10}$, pero que no solo no coincide con la composición de Rizi sino que concuerda plenamente con las líneas fundamentales del Cristo en el Pretorio de Ruiz González, a lo que hay que sumar que su trazo suelto y expresivo remite directamente a los dibujos de este último ${ }^{11}$. El marco arquitectónico desarrollado en el lienzo del Prado es una traslación literal del esbozado en el folio de la Biblioteca Nacional: ambos presentan una amplia escalinata que conduce a un estrado situado en segundo plano, delimitado por columnas y por una balaustrada en la parte izquierda, que deja ver al fondo una arcada de medio punto y una fachada adintelada en el lado derecho (figs. 3 y 4). Ruiz González incrementó el número de figuras en el modelo al óleo, si bien la disposición de los personajes principales coincide con lo planteado del rasguño: varios ángeles coronan la escena, un magistrado aparece bajo palio a la derecha del estrado, dos soldados descienden desde el lado derecho de éste hacia la escalinata y en primer término la composición se cierra a la derecha con una figura de perfil y a la izquierda con otra de espaldas que marca una diagonal. La rotundidad curvilínea con la que esta última se define en el

\footnotetext{
${ }^{7}$ Óleo sobre lienzo, 110,5 x 85,5 cm. Cádiz, Colección Helena Rivero. Se conocen otros dos estudios preliminares al óleo para esta composición, menos acabados y de dimensiones más reducidas (ambos miden 90 x $70 \mathrm{~cm}$.) que el de la colección Helena Rivero y que a diferencia de éste no están firmados. De Carlos Varona plantea que fue uno de estos dos el que hizo las veces modelo de presentación, mientras que el firmado por Coello se trata en su opinión de un ricordo realizado tras la finalización del cuadro de altar. Véase: De Carlos Varona 2013, pp. 321-323, 343-345. Gutiérrez Pastor, por su parte, deja abierta la posibilidad de que el estudio firmado sea un ricordo, como plantea De Carlos Varona, o bien el modelo de presentación, como defiende Aterido. Véase: Gutiérrez Pastor, 2014: 104-105. Aterido, 2007: 116-121.

${ }^{8}$ Montes/Quesada, 2009: 46-49. Basanta, 2000: 114, 133-134, 173, 219. Palomino, 1988 (1 $1^{\text {a }}$ ed. 1724): 390. En el templo madrileño se conservan tanto el lienzo definitivo, que según Palomino fue retocado por José Jiménez Donoso a la muerte de Rizi, como el modelo de presentación. Tras el incendio que arrasó la iglesia el 16 de agosto de 1824 el cuadro de altar fue restaurado por Nicolás Lameyra y más tarde por José de San Martín.

${ }^{9}$ Palomino dice de Ruiz González que "tuvo gran facilidad en hacer dibujos de cualquier asunto, y así dejó hechos innumerables; pero a el mismo paso tenía tal flujo de firmar, que aunque fuese una mala figura, de academia, o un mal rasguño, no había de quedar sin firma. Y así no hay pintura suya grande, ni pequeña, que no esté firmada". Palomino, 1988 ( $1^{\text {a }}$ ed. 1724): 548

${ }^{10}$ Lápiz negro sobre papel de estraza verjurado, 364 x $199 \mathrm{~mm}$, Dib/13/2/40. Montado sobre una cartulina $(450 \mathrm{x}$ $228 \mathrm{~mm}$ ) con línea de encuadre trazada a lápiz. El folio presenta en el ángulo inferior derecho del recto una inscripción manuscrita a tinta parda (cuadro de San / Gines ?) y otra manuscrita a lápiz (Rizi [cortada] —- Rizi), esta última realizada con la misma letra que la manuscrita a lápiz en el ángulo inferior derecho del passepartout (F. Rizi). Asimismo presenta el sello de la colección Carderera (L.432) a tinta azul y cortado en el margen inferior del recto, y el de la Biblioteca Nacional de España (L.398) de nuevo a tinta azul, en el margen derecho del recto. El término rasguño que empleamos para referirnos a este folio fue definido por Palomino en el diccionario antes mencionado como "un dibujo en apuntamiento, ó tanteo", definición que se ajusta bien al apunte de la Biblioteca Nacional que muestra la idea preliminar para una composición apenas esbozada. Carducho había equiparado las categorías de rasguño y esquizo, del italiano schizzo, que Varasi definió como: "una prima sorte di disegni che si fanno per trovare il modo delle attitudini et il primo componimento dell'opra". Carducho, 1979 (1ª ed. 1633): 385-386. Barocchi 1979: 1921-1922.

${ }^{11}$ Para los dibujos de Ruiz González véase: López Sánchez, 2007: 185-201.
} 

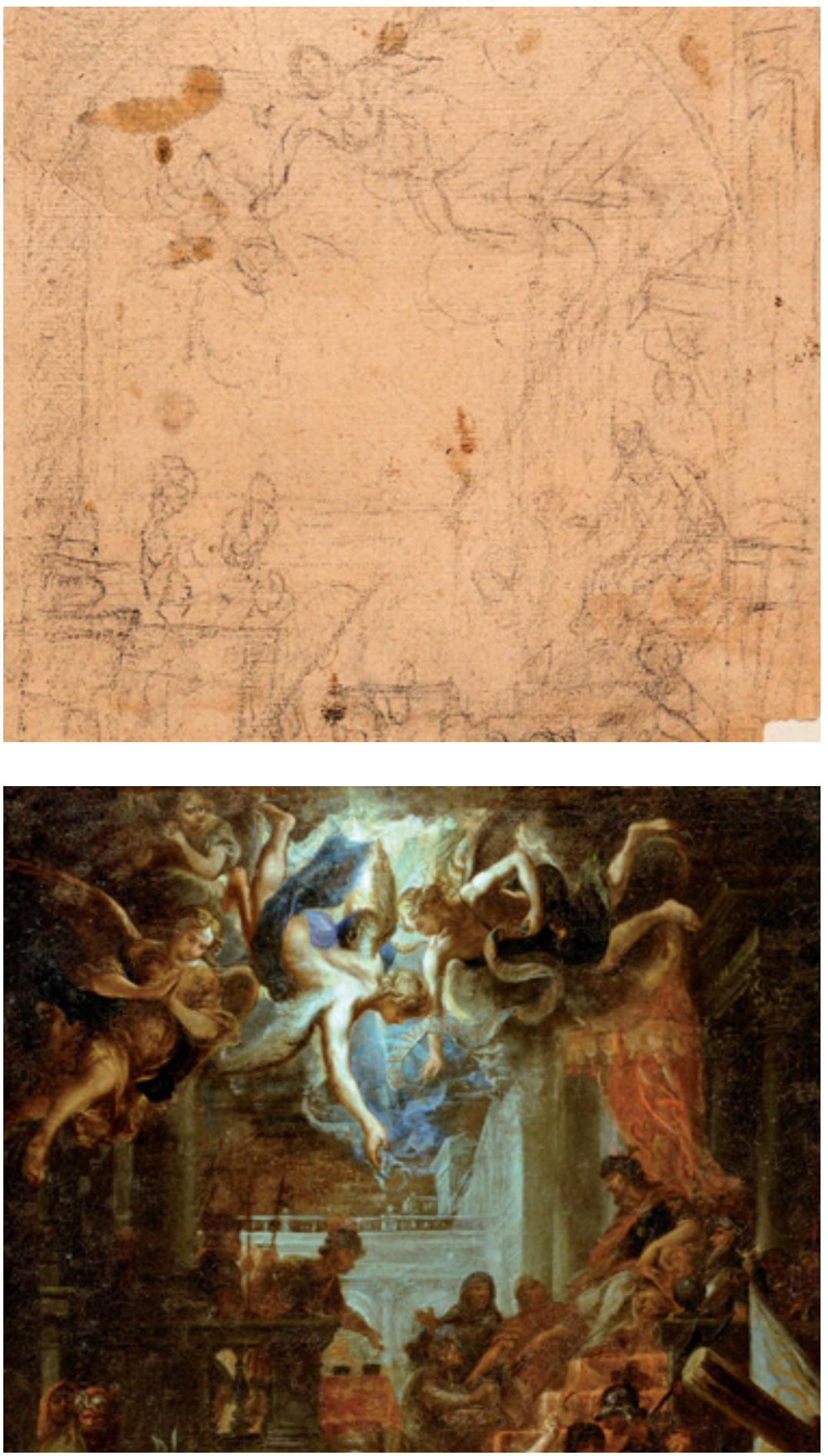

Fig. 3. Detalle de la fig. 2.

Fig. 4. Detalle de la fig. 1.

dibujo de la Biblioteca Nacional concuerda con los tipos físicos de la pintura de Ruiz González. La única variante significativa entre el folio y el modelo al óleo afecta al personaje central, que en ambos casos es conducido por un sayón con un dogal; pero mientras la figura principal del lienzo es Cristo que avanza con las manos atadas a la espalda, el dibujo presenta un personaje mas-

Arch. esp. arte, LXXXIX, 354, ABRIL-JUNIO 2016, 194-201

ISSN: 0004-0428, eISSN: 1988-8511, doi: 10.3989/aearte.2016.13 
culino que alza su brazo y su rostro al cielo, actitud poco habitual en el episodio del pretorio. De modo que esta variación, mínima a nivel formal, resulta sin embargo fundamental para el significado de la escena, lo que parece indicar que el apunte de la Biblioteca Nacional se trata de un estudio de Ruiz González para un asunto similar -probablemente el martirio de un santo-, reaprovechado más tarde en la composición de Cristo en el pretorio, que como hemos detallado presenta evidentes paralelismos con el folio, elocuentes de la relación entre ambos.

El trazo de este rasguño es muy cercano al de otros dibujos a lápiz de Ruiz González y en concreto está estrechamente relacionado con dos Estudios de figuras conservados en el Prado (figs. 5 y 6$)^{12}$ en los que, al igual que en el folio de la Biblioteca Nacional, el artista dio a las figuras el tratamiento de maniquíes, trazando en primer lugar los cuerpos desnudos que solo en algunos casos cubrió posteriormente con paños, definiendo las anatomías con líneas ondulantes y omitiendo la descripción detallada de los rasgos del rostro, que redujo a un ovalo en ocasiones atravesado por dos líneas perpendiculares. El pintor siguió este mismo procedimiento en el dibujo que Sánchez Cantón identificó como preparatorio para los Cardenales Jesuitas de la sacristía del Colegio Imperial $^{13}$, en el que describió de manera esquemática los cuerpos de los tres personajes representados, trazando posteriormente las vestimentas que cubren las dos figuras de la derecha.

El segundo de los folios que adscribimos a Ruiz González presenta en la mitad superior un apunte para la degollación de San Juan Bautista y en la inferior dos estudios para una figura fe-

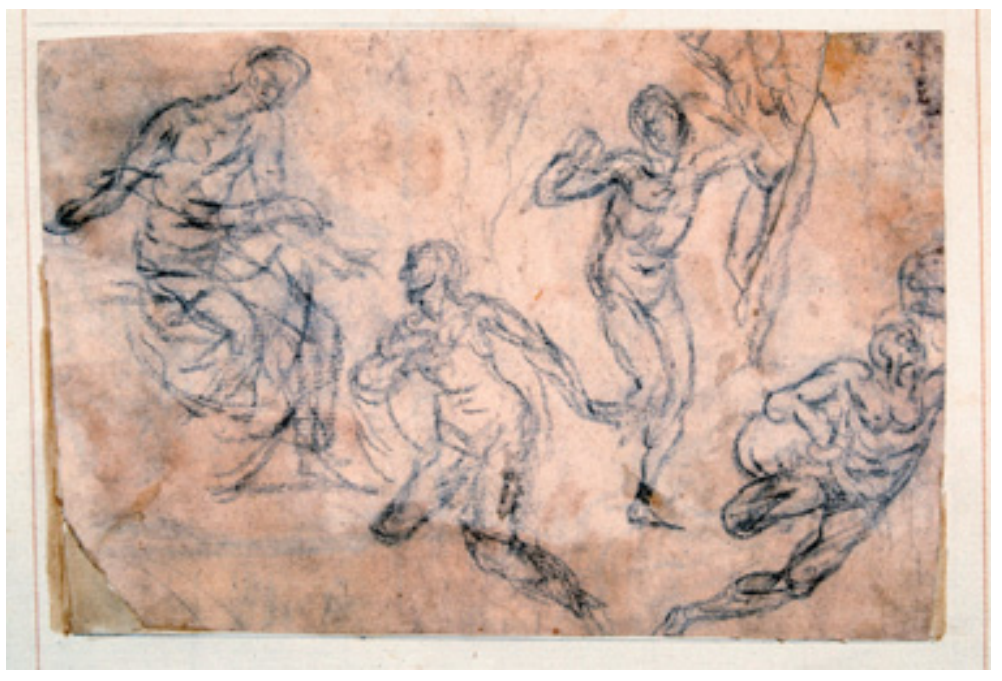

Fig. 5. Pedro Ruiz González, Estudio de Figuras. Museo Nacional del Prado, Madrid.

${ }^{12}$ Lápiz negro sobre papel verjurado, 112 x $165 \mathrm{~mm}, \mathrm{n}^{\circ}$ inv. D186. Lápiz negro sobre papel verjurado, 154 x 241 mm, nº inv. D187. Pérez Sánchez 1972b: 125-126. Sánchez Cantón, 1943: 403. López Sánchez, 2007: 126, 189-190. López Sánchez considera que estos dibujos fueron realizados para una misma serie de pinturas y los vincula con un ciclo de la Pasión de Cristo con el que relaciona el Cristo en el Pretorio. Se piensa que pertenece también a este ciclo un Ecce Homo ante Caifás conservado en Szepmuveszeti Muzeum de Budapest (óleo sobre lienzo, 97 x 71,5 cm., $\mathrm{n}^{\circ}$ inv. 366). Véase: Nyerges, 2008: 180-181.

${ }^{13}$ Lápiz negro sobre papel de estraza verjurado, 107 x $167 \mathrm{~mm}, \mathrm{n}^{\circ}$ inv. D185. En la Biblioteca Nacional se conserva otro apunte para esta serie (Dib/16/3/10). López Sánchez, 2007: 195-196. Pérez Sánchez 1972b: 125. Sánchez Cantón 1943: 403. Sobre los cuatro Cardenales pintados por Ruiz González y destruidos en 1936, véase: Sánchez Cantón 1943: 399-400. Ceán, 1800: 28. Ponz, 1793: 92-93. 


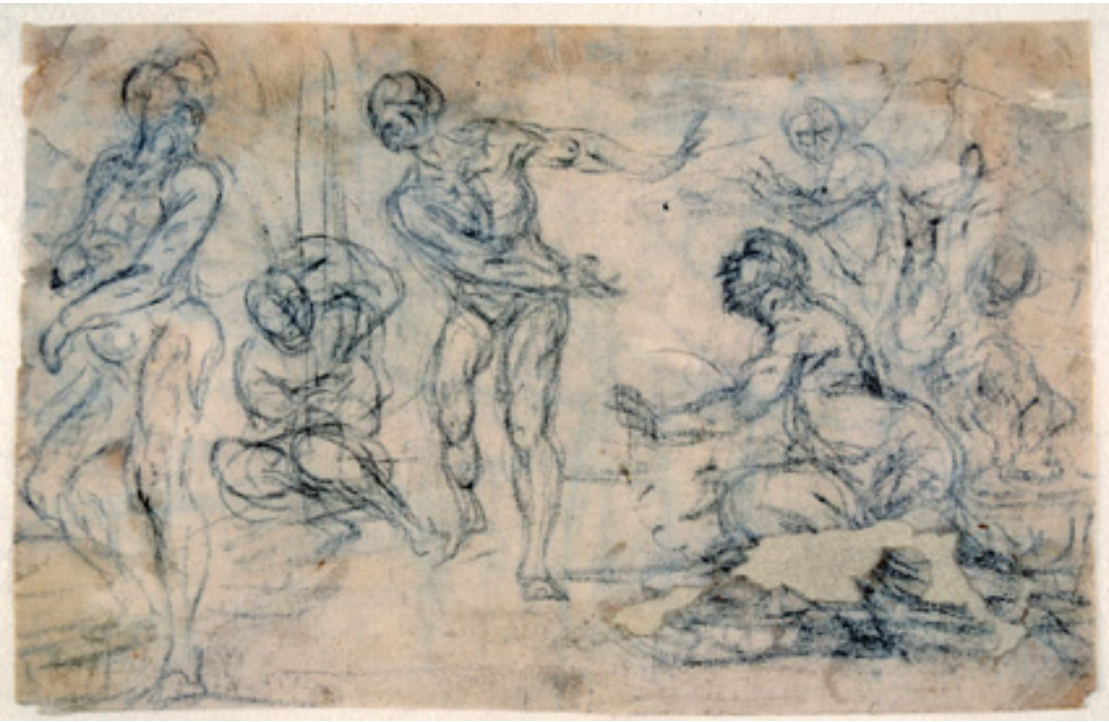

Fig. 6. Pedro Ruiz González, Estudio de Figuras. Museo Nacional del Prado, Madrid.

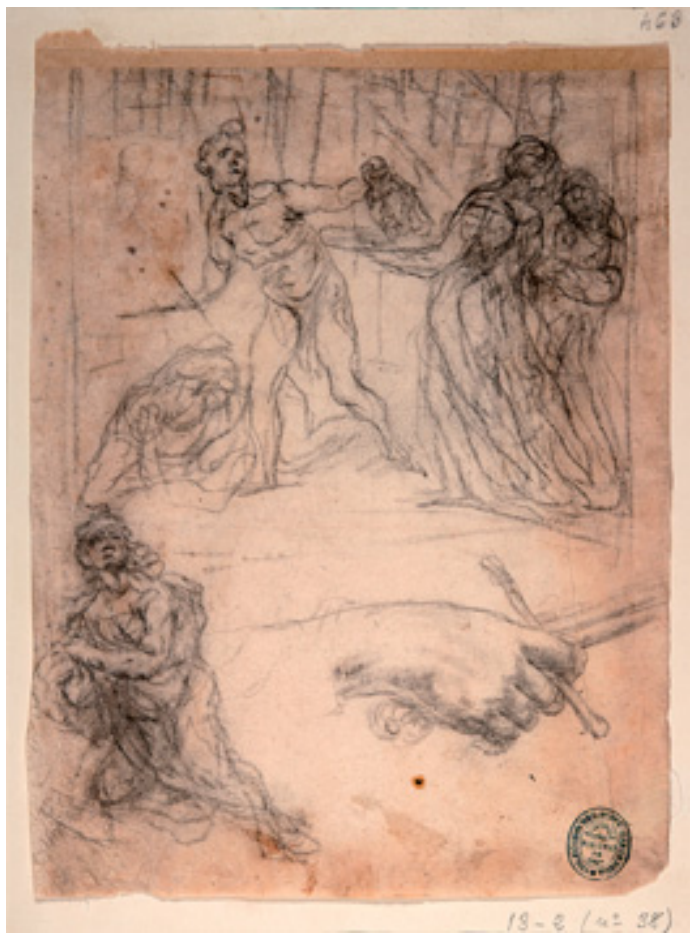

Fig. 7. Aquí atribuido a Pedro Ruiz González, Estudios para la degollación de San Juan Bautista. Biblioteca Nacional de España, Madrid.

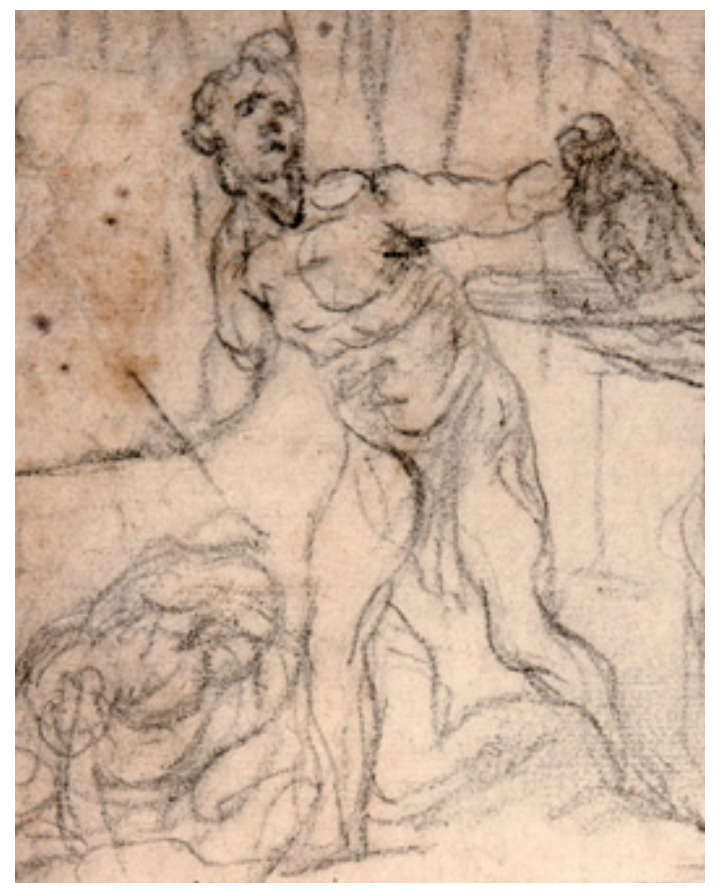

Fig. 8. Detalle de la fig. 7.

Arch. esp. arte, LXXXIX, 354, ABRIL-JUNIO 2016, 194-201

ISSN: 0004-0428, eISSN: 1988-8511, doi: 10.3989/aearte.2016.13 


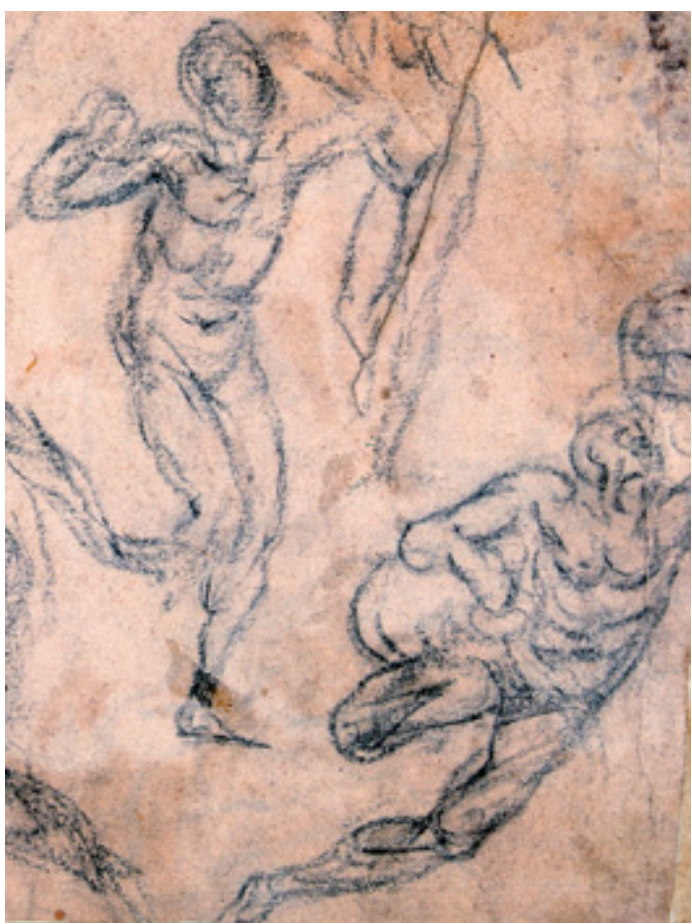

Fig. 9. Detalle de la fig. 5.

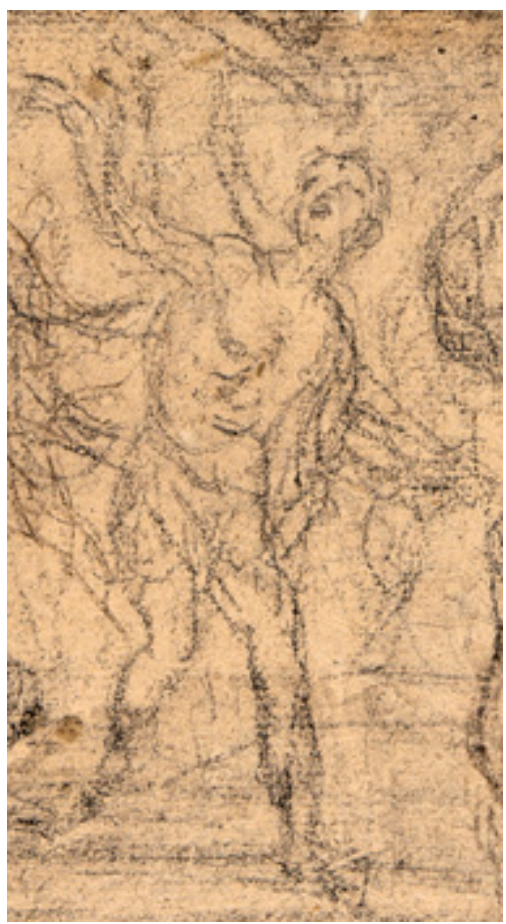

Fig. 10. Detalle de la fig. 2.

menina arrodillada y una mano empuñando una espada respectivamente (fig. 7$)^{14}$. De nuevo se observan coincidencias formales con los dibujos ya conocidos del pintor, así por ejemplo, el torso del verdugo se define con trazos cortos y curvos y las piernas con líneas ondulantes, al igual que sucede en los Estudios del Prado y en la figura central del rasguño de la Biblioteca Nacional (figs. 8, 9 y 10). Al carácter abreviado de los esbozos para la degollación y la figura femenina arrodillada se contrapone la minuciosidad del tercero de los apuntes realizados en la hoja, que seguramente es un estudio para un detalle de la escena superior, en el que el volumen de la mano se ha modelado cuidadosamente empleando lápiz negro difuminado en contraste con las reservas de papel correspondientes a las zonas iluminadas.

Las coincidencias existentes entre los dos folios de la Biblioteca Nacional que aquí presentamos y los dibujos conocidos de Pedro Ruiz González, caracterizados por el empleo de trazos expresivos y ondulantes de lápiz negro y por la reducción de las anatomías a su estructura básica, permite atribuirlos a este pintor, dando así un paso más en la definición del corpus gráfico de la pléyade de artistas que trabajaron en Madrid en las últimas décadas del siglo XVII.

\footnotetext{
${ }^{14}$ Lápiz negro sobre papel verjurado, 240 x 185 mm, Dib/13/2/38. Papel con filigrana formada por el escudo de Génova (corona sobre un óvalo con la cruz de San Jorge inscrita y flanqueado por dos grifos rampantes) y dos círculos, el primero de ellos tiene inscritos dos círculos unidos por una recta, y el segundo un número uno. Filigrana similar a Balmaceda, 2005: n⿳3 315, 317, 322, 337. El folio está montado sobre una cartulina (268 x $199 \mathrm{~mm})$ y presenta el sello de la colección Carderera (L.432) a tinta azul en el ángulo inferior derecho del recto y un fragmento de papel añadido en la parte superior.
} 


\section{BIBLIOGRAFÍA}

Agulló Cobo, Mercedes (1978): Noticias sobre pintores madrileños de los siglos XVI y XVII. Granada: Universidad de Granada.

Aterido, Ángel (coord.) (2007): El tiempo de la pintura: maestros españoles de los siglos XVI al XIX. Madrid: Coll \& Cortés.

Balmaceda, José Carlos (2005): La contribución genovesa al desarrollo de la manufactura papelera española. Málaga: Imagraf.

Barcia, Ángel Ma (1906): Catálogo de la colección de dibujos originales de la Biblioteca Nacional. Madrid: Tipografía de la Revista de Archivos, Bibliotecas y Museos.

Barocchi, Paola (ed.) (1979): Scritti d'Arte del Cinquecento. Vol. VIII. Disegno. Turín: Giulio Einaudi.

Barrio Moya, José Luis (1995): “Algunas noticias sobre el pintor Pedro Ruiz González". En: Boletín del Seminario de Estudios de Arte y Arqueología, 61, pp. 413-423.

Basanta Reyes, Ma Belén (2000): “La parroquia de San Ginés de Madrid. Datos Histórico Artísticos”. En: Cuadernos de arte e iconografia, IX, 17-18, pp. 11-402.

Baticle, Jeannine (1964): "La fundación de la Orden Trinitaria, de Carreño de Miranda". En: Goya, 63, pp. 140-153.

Baticle, Jeannine (1965): "La genèse d'une peinture". En: Bulletin du Laboratoire du Musée du Louvre, 10, pp. 15-34.

Carducho, Vicente (1979, $1^{\circ}$ ed. 1633), Diálogos de la pintura, su defensa, origen, esencia, definición, modos y diferencias, Calvo Serraller, Francisco (ed.). Madrid: Turner.

Ceán Bermúdez, Juan Agustín (1800): Diccionario de los más ilustres profesores de las bellas artes en España, t. IV. Madrid : Imprenta de la viuda de Ibarra.

De Carlos Varona, María Cruz (2013): "Profecía e inmaculismo en el convento de San Plácido: reconsiderando la «Encarnación» de Claudio Coello”. En: Rodríguez Rebollo, Ángel (coord.), Carlos II y el arte de su tiempo. Madrid: Fundación Universitaria Española, pp. 319-346.

Gutiérrez Pastor, Ismael (2014): "Encarnación de la Virgen con los profetas y las sibilas que la predijeron. Boceto para el retablo mayor de San Plácido". En: A su imagen. Arte, cultura y religión. Cat exp. Madrid, Centro Cultural de la Villa, noviembre 2014 - abril 2015. Madrid: A su imagen, pp. 104-105.

López Sánchez, Fernando (2007): Pedro Ruiz González (h.1638/1642-1706). Pintor Barroco Madrileño. Cat. exp. Madrid, Conde Duque, junio-julio 2007, Madrid: Ayuntamiento de Madrid, Área de Gobierno de Las Artes.

Montes, José Luis / Quesada Varela, José Ma (2009): Real Parroquia de San Ginés. Guía del Patrimonio Cultural. León: Edilesa.

Nyerges, Éva (2008): Spanish paintings: the collections of the Museum of Fine Arts of Budapest. Budapest: Museum of Fine Arts.

Palomino, Antonio (1988, $1^{\text {a }}$ ed. 1724): El museo pictórico y escala óptica. Vol. III. El Parnaso español pintoresco laureado. Madrid: Aguilar.

Pemán, César (1944): "Un cuadro desconocido de Pedro Ruiz González”. En: Archivo Español de Arte, XVII, 63, pp. $179-180$.

Pérez Sánchez, Alfonso E. (1972): Mostra di disegni spagnoli. Cat. exp. Florencia, Galleria degli Uffizi, 1972. Florencia: Leo S. Olschki.

Pérez Sánchez, Alfonso E. (1972b): Museo del Prado. Catálogo de dibujos. T. I. Dibujos españoles, siglos XV-XVII. Madrid: Museo Nacional del Prado.

Pérez Sánchez, Alfonso E. (1980): El dibujo español de los siglos de oro. Cat. exp. Madrid, Palacio de Bibliotecas y Museos, mayo 1980. Madrid: Dirección General del Patrimonio Artístico, Archivos y Museos.

Pérez Sánchez, Alfonso E. (1986): Historia del dibujo en España de la Edad Media a Goya. Madrid: Cátedra.

Pérez Sánchez, Alfonso E. (1986b): Carreño, Rizi, Herrera y la pintura de su tiempo (1650-1700). Cat. exp. Madrid, Palacio de Villahermosa, enero-marzo 1986. Madrid: Ministerio de Cultura.

Ponz, Antonio (1793): Viage de España, t. V. Madrid: Imprenta de la Viuda de Ibarra.

Quesada Varela, José Ma (1999): "Nueve pinturas madrileñas inéditas del siglo XVII”. En: Goya, 271-272, pp. 213-224.

Sánchez Cantón, Francisco Javier (1943): "Pedro Ruiz González. Pintor de la Escuela Madrileña". En: Archivo Español de Arte, XVI, 60, pp. 399-403.

Sullivan, Edward J. / Mallory, Nina A. (1982): Painting in Spain 1650-1700 from North American Collections. Cat. exp. The Art Museum, Princeton University, abril-junio 1982, The Detroit Institute of Arts, julio-septiembre 1982. Princeton: Princeton University.

Urrea Fernández, Jesús (1975): “Obras de pintores madrileños: B. de Castrejón, A. van de Pere y P. Ruiz González”. En: Boletín del Seminario de Estudios de Arte y Arqueología, 40-41, pp. 707-712.

Fecha de recepción: 19-I-2015

Fecha de aceptación: 17-VI-2015

Arch. esp. arte, LXXXIX, 354, ABRIL-JUNIO 2016, 194-201

ISSN: 0004-0428, eISSN: 1988-8511, doi: 10.3989/aearte.2016.13 